\title{
Anti-CD47 Monoclonal Antibody
}

National Cancer Institute

\section{Source}

National Cancer Institute. Anti-CD47 Monoclonal Antibody. NCI Thesaurus. Code C159583.

Any monoclonal antibody that targ ets the CD47 antigen. 